\title{
AVALIAÇÃO DE DANO MECÂNICO EM SEMENTES DE FEIJÃO POR MEIO DE CONDUTIVIDADE ELÉTRICA
}

\author{
Ednilton Tavares de Andrade' ${ }^{1}$, Paulo Cesar Corrêa ${ }^{2}$, José Helvecio Martins ${ }^{3}$ \\ e Eveline Mantovani Alvarenga ${ }^{4}$
}

\begin{abstract}
RESUMO
Este trabalho foi realizado com o intuito de se avaliar danos mecânicos em sementes de feijão (Phaseolus vulgaris L.) variedade Ouro Negro 1992, por meio de condutividade elétrica da solução contendo as sementes danificadas devido ao choque mecânico controlado, com utilização de três níveis de velocidade de choque. Para se comparar a queda de qualidade devido ao choque mecânico, foram utilizados também o teste-padrão de germinação e a avaliação visual dos danos mecânicos, cujos resultados permitiram concluir que a utilização da condutividade elétrica da solução contendo as sementes pode ser correlacionada com o índice de danos mecânicos podendo, portanto, ser utilizada para avaliar danos mecânicos em sementes.
\end{abstract}

Palavras-chave: sementes de feijão, dano mecânico, condutividade elétrica

\section{EVALUATION OF MECHANICAL DAMAGE IN EDIBLE BEAN SEEDS BY ELECTRICAL CONDUCTIVITY}

\begin{abstract}
The aim of this work was to evaluate mechanical damages in edible black bean seeds (Phaseolus vulgaris L.), variety "Ouro Negro 1992", caused by controlled mechanical impact by measuring the electrical conductivity of the solution containing the seeds. Three levels of mechanical impact were used in the experiment. The standard germination test was also used to compare the decrease in the seed quality. The results led to conclude that the electrical conductivity of the solution containing the seeds may be correlated to the mechanical damage and therefore, can be used to evaluate mechanical damages in seeds.
\end{abstract}

Key words: Edible bean seeds, mechanical damage, electrical conductivity

\section{INTRODUÇÃO}

$\mathrm{O}$ atraso na época de colheita, a alta temperatura de secagem e os danos mecânicos são, dentre outros fatores, os principais responsáveis pela baixa qualidade da semente, insumo básico para produção dos produtos agrícolas (Vieira et al., 1993).

Segundo CARVALHO \& NAKAGAWA (1988) a injúria mecânica, juntamente com a mistura varietal, é apontada pelos tecnologistas como um dos mais sérios problemas da produção de sementes. A injúria mecânica é conseqüência, na sua maior

\footnotetext{
${ }^{1}$ Doutorando em Engenharia Agrícola, Bolsista do CNPq, UFV, Dep. Engenharia Agrícola, Campus da UFV. 36571-000, Viçosa, MG, etavares@alunos.ufv.br.

${ }^{2}$ Prof. Adjunto, Bolsista do CNPq, Depto. de Eng. Agrícola, Universidade Federal de Viçosa, Viçosa, MG

${ }^{3}$ Prof. Titular, Bolsista do CNPq, Depto. de Eng. Agrícola, UFV, Viçosa, MG, jmartins@ @ail.ufv.br

${ }^{4}$ Profa Adjunta, Depto. de Fitotecnia, UFV, Viçosa, MG
} 
parte, da mecanização das atividades agrícolas, constituindose em um problema praticamente inevitável, pois as principais fontes desta injúria se encontram em todas as etapas do processo produtivo: na colheita, no beneficiamento, no armazenamento e no transporte.

Vários fatores, como temperatura de secagem, tensão aplicada na quebra das sementes, umidade, dureza e características genotípicas do produto, influenciam a susceptibilidade à quebra, a qual se refere ao potencial de fragmentação do produto quando este é submetido a uma força de impacto durante o beneficiamento ou transporte (Gunasekaran \& Muthukumarappan 1993).

Em geral, recomenda-se iniciar a colheita tão $\operatorname{logo}$ as sementes de feijão atinjam um teor de umidade em torno de 20\% (Araújo et al., 1984).

A colheita é uma das mais importantes fontes de injúria mecânica. Na colhedora, a injúria mecânica às sementes ocorre principalmente no momento da debulha, ou seja, no momento em que forças consideráveis são aplicadas sobre a semente, a fim de separá-las da estrutura que as contém.

A armazenagem não é uma fonte de injúria mecânica importante e durante ela, a semente ensacada ou a granel está sujeita a esforços de compressão, por causa da coluna que repousa sobre ela. Os danos no armazenamento são ocasionados principalmente pelas quedas sucessivas, a partir de alturas variadas e por impactos diversos. Desde que chegam do campo até o momento em que são armazenadas, as sementes passam por uma série de máquinas e, destas, para depósitos, mediante elevação em elevadores de caneca e quedas dentro de silos ou depósitos.

Os processos de carregamento e descarregamento de sementes ensacadas e a granel, dos caminhões ou dos vagões, quando não são bem supervisionados também podem acarretar danificações mecânicas ao produto.

O teor de umidade é fator de grande influência na percentagem final de danos mecânicos em sementes, pois sementes secas têm maior susceptibilidade a danos mecânicos que sementes úmidas. Pickett (1973) estudando danos mecânicos e perdas durante o processo de colheita do feijão, concluiu que os danos mecânicos durante a colheita dependem, principalmente, do teor de umidade e da velocidade do cilindro da colhedora.

Segundo Costa et al. (1979) os danos mecânicos imediatos (visíveis) são representados por tegumentos rompidos, cotilédones separados e quebrados e podem ser observados pela análise visual; já os danos latentes correspondem àqueles que se manifestarão durante o armazenamento, com a queda da qualidade fisiológica da semente, sendo representados por trincas microscópicas e abrasões.

Quando os danos mecânicos são visíveis (sementes partidas e com rupturas no tegumento) essas sementes podem ser separadas, durante a limpeza, por máquinas apropriadas que as separam de acordo com suas propriedades físicas. Danos internos e ruptura de pequena proporção no tegumento são difíceis de ser detectados e tornam as sementes susceptíveis a fungos e insetos, o que, juntamente com sua posterior propagação, diminuirá sua qualidade fisiológica (Chaves et al., 1992).

A qualidade da semente é afetada pela temperatura e umidade relativa do ar de secagem e, conseqüentemente, pela taxa de secagem. Radajewski et al. (1992), estudando a secagem de feijão, concluíram que a temperatura do ar de secagem e, conseqüentemente, a taxa de secagem têm grande efeito sobre a qualidade do produto final.

A condutividade elétrica da solução de embebição de sementes tem sido proposta como teste para avaliar-se o vigor, visto que o valor da condutividade é função da quantidade de lixiviados na solução, a qual está diretamente associada à integridade das membranas celulares; logo, membranas mal estruturadas e células danificadas estão, geralmente, associadas ao processo de deterioração da semente e, portanto, a sementes de baixo vigor ( Heslehurst, 1988).

O método de avaliação da qualidade do grão ou semente, pela condutividade elétrica da solução de lixiviados, pode ter modificada sua metodologia para que se possa avaliar o nível de danificação mecânica em grãos, em função do tempo de embebimento, com ou sem agitação mecânica da solução contendo as sementes ( Matthews \& Rogerson, 1976). Este método, pela simplicidade de realização, poderia ser utilizado até na propriedade, além de poder avaliar níveis diferentes de danos internos e externos em grãos, embora a sua principal desvantagem seja o tempo requerido para sua realização (Couto et al., 1998).

A quantidade de exsudado da semente, na água de embebição, pode ser influenciada pelo estádio de desenvolvimento no momento da colheita, pelo grau de deterioração e pela incidência de dano causado pela velocidade de embebição, pela ocorrência de injúrias no tegumento da semente, pela temperatura e tempo de embebição, pelo genótipo, pela idade e cor da semente, dentre outros fatores (Vieira \& Carvalho, 1994).

Em face ao que foi exposto, este trabalho teve como objetivo avaliar danos mecânicos em sementes de feijão (Phaseolus vulgaris L.) variedade Ouro Negro 1992, por meio da adequação do método de condutividade elétrica da solução contendo as sementes danificadas por impacto mecânico controlado em três níveis de velocidade e com diferentes teores de umidade inicial (na colheita) e teores de umidade final, depois da secagem.

\section{MATERIAL E MÉTODOS}

Foram utilizadas sementes de feijão (Phaseolus vulgaris L.) variedade Ouro Negro 1992, safra de janeiro de 1996, procedentes do Município de Cajuri, MG. As amostras foram colhidas e trilhadas manualmente; de início, foram colhidas duas amostras de sementes, com diferentes teores de umidade $(33,4$; 29,4 e $25,1 \%$ b.u.). Para cada teor de umidade inicial, foram preparadas amostras acondicionadas em sacos de polietileno e armazenadas em câmara fria a temperatura de, aproximadamente, $5^{\circ} \mathrm{C}$ por 30 dias, até a realização da secagem.

$\mathrm{O}$ teor de umidade inicial das sementes foi determinado pelo método-padrão da estufa, $105 \pm 3^{\circ} \mathrm{C}$, durante $24 \mathrm{~h}$, com duas repetições, de acordo com as Regras para Análise de Sementes (Brasil,1992).

A secagem foi realizada utilizando-se temperatura de, aproximadamente, $35^{\circ} \mathrm{C}$, para garantir a qualidade inicial do produto.

Os experimentos de secagem foram feitos no esquema fatorial 3 x 2, sendo três níveis de umidade inicial $(33,4 ; 29,4$ e $25,1 \%$ b.u.) e dois níveis de umidade final (de aproximadamente, $11 \%$ b.u. e $13 \%$ b.u.) em um delineamento inteiramente casualizado, com três repetições. 
Os testes de secagem foram realizados utilizando-se um secador de laboratório com controle de temperatura e da vazão de ar.

O fluxo de ar foi determinado a partir da velocidade do ar de secagem, determinada por meio de um anemômetro de lâminas rotativas, adaptado à entrada de ar do ventilador e mantido para todos os tratamentos de secagem em, aproximadamente, $10 \mathrm{~m}^{3} \mathrm{~min}^{-1} \mathrm{~m}^{-2}$.

Para cada tratamento de secagem, a umidade relativa e a temperatura do ar foram registradas em um termohigrógrafo e a umidade relativa do ar secante foi calculada pelas equações psicrométricas, por meio de um programa computacional desenvolvido na Universidade Federal de Viçosa, denominado GRAPSI.

\section{Impacto mecânico nas sementes}

Depois da secagem, as sementes foram submetidas a testes de impacto, utilizando-se três níveis de velocidade $(16,5 ; 13,0$ e $10,0 \mathrm{~m} \mathrm{~s}^{-1}$ ).

As sementes foram impactadas utilizando-se o aparelho desenvolvido por Santos (1976) e modificado para as condições deste trabalho, conforme Figura 1.

O impactador era acionado por um motor elétrico de $0,25 \mathrm{cv}$, ligado a três polias de diâmetro diferente e conectadas a um disco rígido de $0,93 \mathrm{~m}$ de diâmetro e massa de $3,247 \mathrm{~kg}$, o qual continha, na sua periferia, uma haste metálica plana que promove o impacto. Cada uma das três polias transfere, por meio de correia, uma rotação para o disco rígido do impactador, medida por um estroboscópio. Estas rotações e as respectivas velocidades foram:

- velocidade de 10,0 $\mathrm{m} \mathrm{s}^{-1}$ (velocidade angular de $645 \mathrm{rpm}$ )

- velocidade de 13,0 $\mathrm{m} \mathrm{s}^{-1}$ (velocidade angular de $839 \mathrm{rpm}$ )

- velocidade de $16,5 \mathrm{~m} \mathrm{~s}^{-1}$ (velocidade angular de $1.064 \mathrm{rpm}$ ).

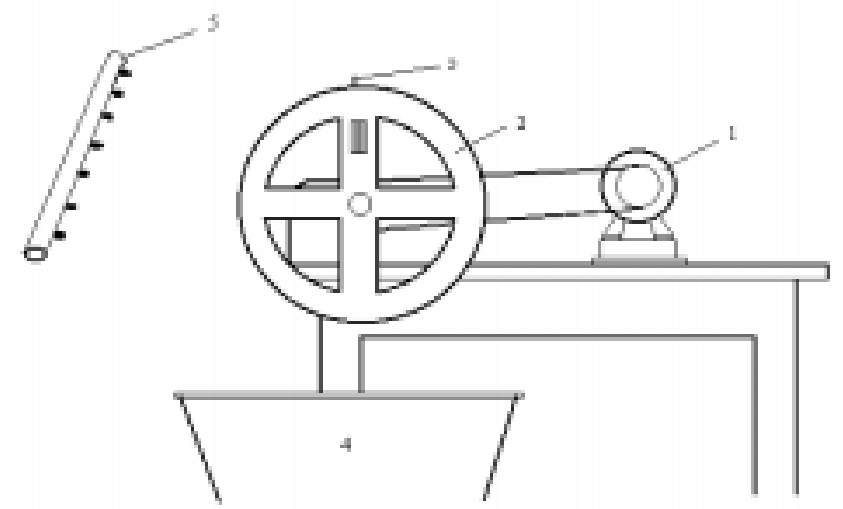

1. Motor elétrico para acionamento do sistema

2. Disco metálico

3. Impactador de haste metálica plana fixa

4. Cesta de flanela para recepção da semente depois do impacto

5. Bastão com fita adesiva para fixação e posicionamento das sementes

Figura 1. Desenho esquemático do impactador e bastão fixação das sementes

As sementes foram posicionadas (hilo e oposto ao hilo, sendo metade em cada posição) em um bastão de madeira, que continha uma fita adesiva presa nas extremidades e possibilitava a fixação das sementes para o impacto. Depois de se fixar as sementes, o bastão era manualmente direcionado para a haste do disco rígido do impactador, para que as sementes pudessem receber o impacto, sendo que, imediatamente depois de receber o impacto, as sementes eram colhidas em uma cesta de flanela, embaladas e mantidas em câmara fria com temperatura e umidade relativa de, aproximadamente, $10^{\circ} \mathrm{Ce} 70 \%$, respectivamente, até o final dos testes, para evitar variações na qualidade inicial das sementes.

\section{Avaliação visual dos danos mecânicos}

Logo depois do tratamento de impacto, foi feita a avaliação visual dos danos ocorridos. Para isto, utilizou-se de uma bancada com fundo branco, que possibilitou melhor observação dos danos, os quais foram classificados da seguinte forma:

- danos severos: sementes partidas ao meio

- danos intermediários: sementes partidas, apresentando partes inteiras maiores que a metade

- danos leves: sementes com o tegumento visualmente rompido.

Depois da separação, conforme o dano, e da pesagem das sementes para cada tipo de dano, foi feito o cálculo da percentagem em peso de sementes danificadas, e de sementes intactas para todos os tratamentos. Como as sementes partidas ao meio (dano severo) são facilmente separadas por máquinas de beneficiamento, estas foram quantificadas em percentagem de peso e retiradas das amostras, descontado seu valor nos testespadrão de germinação (TPG) o qual avalia a viabilidade da amostra de sementes.

\section{Teste-padrão de germinação (TPG)}

Os testes de germinação foram realizados logo depois dos testes de impacto, conforme os critérios estabelecidos pelas Regras para Análise de Sementes (Brasil,1992). Para cada repetição dos tratamentos de impacto foram utilizadas quatro repetições de 50 sementes.

Antes da montagem do teste, as sementes foram tratadas com fungicida (Benlate) proporcionalmente na dosagem de $1 \mathrm{~g}$ para $1 \mathrm{~kg}$ de sementes.

As sementes, tendo como substrato papel tipo "germitest", umedecido com água deionizada, foram colocadas para germinar, a temperatura aproximada de $25^{\circ} \mathrm{C}$, em um germinador. As avaliações foram realizadas aos cinco e nove dias depois da instalação do teste e os resultados expressos em percentagem de plântulas normais.

$\mathrm{Na}$ primeira avaliação foram contadas e eliminadas as plântulas normais e as sementes mortas ou infeccionadas que pudessem contaminar as demais.

No nono dia foi realizada a contagem final de plântulas normais, plântulas anormais e sementes mortas ou deterioradas. O resultado da germinação foi expresso pela percentagem média de plântulas normais das duas avaliações.

\section{Teste de condutividade elétrica}

Foi utilizado o sistema de copo ou massa, conforme metodologia recomendada por Krzyzanowski et al. (1991) e Vieira \& Carvalho (1994).

As amostras, em 4 repetições de 50 sementes, foram pesadas, com precisão de $0,01 \mathrm{~g}$ e colocadas em copos de plástico (200 mL) aos quais foram adicionados $75 \mathrm{~mL}$ de água deionizada; em seguida, os copos foram colocados em um germinador, regulado para a temperatura de $25^{\circ} \mathrm{C}$, onde permaneceram 
durante 24 horas. Decorrido esse período, os recipientes foram retirados do germinador, suavemente agitados e, imediatamente, procederam-se às medições.

A condutividade elétrica da solução contendo as sementes foi obtida dividindo-se, para cada repetição dos testes, o valor da condutividade $\left(\mu \mathrm{S} \mathrm{cm}^{-1}\right)$ lida no condutivímetro, pela massa (g) das 50 sementes, sendo seu valor expresso em $\mu \mathrm{S} \mathrm{cm}^{-1} \mathrm{~g}^{-1}$, cujo resultado final foi obtido pela média dos valores determinados em cada repetição.

\section{RESULTADOS E DISCUSSÃO}

Na Tabela 1 são mostrados os dados médios de temperatura e umidade relativa do ar para cada tratamento de secagem.

Tabela 1. Resumo das temperaturas médias de secagem e umidade relativa, para os diversos tratamentos

\begin{tabular}{cccc}
\hline \multicolumn{2}{c}{ Teores de Umidade* $(\%$ b.u $)$} & $\begin{array}{c}\text { Temperaturas } \\
\left({ }^{\circ} \mathrm{C}\right)\end{array}$ & $\begin{array}{c}\text { UR** } \\
(\%)\end{array}$ \\
\hline Ui & Uf & $35,0 \pm 2,0$ & 47,7 \\
$23,4 \%$ & $11,0 \%$ & $35,0 \pm 2,0$ & 47,2 \\
$25,1 \%$ & $11,0 \%$ & $35,0 \pm 2,0$ & 48,0 \\
$33,4 \%$ & $11,0 \%$ & $35,0 \pm 2,0$ & 45,6 \\
$29,4 \%$ & $13,0 \%$ & $35,0 \pm 2,0$ & 43,9 \\
$25,1 \%$ & $13,0 \%$ & $35,0 \pm 2,0$ & 42,0 \\
\hline
\end{tabular}

*Ui $=$ Umidade inicial (colheita) Uf $=$ Umidade final (secagem)

**UR $=$ Umidade relativa do ar

\section{Efeito da injúria mecânica nas sementes}

A Tabela 2 contém os resultados da condutividade elétrica da solução obtidos experimentalmente, da percentagem de germinação e da avaliação visual das danificações mecânicas nas sementes, depois do impacto mecânico. Observa-se que a intensidade de injúria mecânica se eleva com o aumento da velocidade de impacto ao qual as sementes são impostas, apresentando maior intensidade para sementes com menor teor de umidade final (11,0\% b.u.). Newbery et al. (1980) Paulsen et al. (1981) e Evans et al. (1990) trabalhando com danos mecânicos em soja, concluíram também que o teor de umidade e a velocidade de impacto são fatores importantes que definem a severidade dos danos mecânicos nas sementes.

Pela Tabela 2 observa-se que o nível de danificações às sementes foi variável conforme a velocidade de impacto. A Figura 2 ilustra os níveis de dano nas sementes depois do impacto, danos estes classificadas como tegumento rompido, cotilédone separado e partido. Durante o experimento pode-se observar que sementes impactadas com velocidades mais elevadas $\left(16,5 \mathrm{~m} \mathrm{~s}^{-1}\right)$ apresentaram os piores resultados de integridade física, observando-se desde rompimento do eixo hipocótilo-radícula até separação dos cotilédones (Figura 2). Quanto mais proeminentes foram esses efeitos, as sementes apresentaram rompimento na parte do tegumento que sofreu o impacto; já quando a velocidade de impacto foi menor $\left(10 \mathrm{~m} \mathrm{~s}^{-1}\right)$ os efeitos desta danificação não foram tão visíveis, o que pode ser explicado pelo fato de que sementes aparentemente intactas, depois de sofrerem impacto apresentam danificações e rompimento da estrutura celular interna, que só serão detectados por um teste de vigor.
Tabela 2. Valores experimentais de condutividade elétrica, percentagem de germinação e percentagem de danos ocorridos nas sementes, em função da umidade inicial na colheita, umidade final depois da secagem e velocidade de impacto mecânico nas sementes

\begin{tabular}{|c|c|c|c|c|c|c|}
\hline \multirow[t]{2}{*}{ Característica } & \multirow{2}{*}{$\begin{array}{c}\text { Ui } \\
\text { (\%b.u.) }\end{array}$} & \multirow{2}{*}{$\begin{array}{c}\text { Uf } \\
\text { (\%b.u.) }\end{array}$} & \multicolumn{4}{|c|}{ Velocidade de Impacto $\left(\mathrm{m} \mathrm{s}^{-1}\right)$} \\
\hline & & & 0,0 & 10,0 & 13,0 & 16,5 \\
\hline \multirow{6}{*}{$\begin{array}{l}\text { Condutividade } \\
\left(\mu \mathrm{S} \mathrm{cm}^{-1} \mathrm{~g}^{-1}\right)\end{array}$} & 25,1 & 11,0 & 80,65 & 114,57 & 115,49 & 115,16 \\
\hline & 29,4 & 11,0 & 80,67 & 120,19 & 118,10 & 123,24 \\
\hline & 33,4 & 11,0 & 81,84 & 134,86 & 135,60 & 142,72 \\
\hline & $\overline{25,1}$ & 13,0 & 77,15 & 94,90 & 94,09 & $\overline{100,11}$ \\
\hline & 29,4 & 13,0 & 79,45 & 99,74 & 101,46 & 103,91 \\
\hline & 33,4 & 13,0 & 81,84 & 107,91 & 106,41 & 104,94 \\
\hline \multirow{6}{*}{$\begin{array}{c}\text { Germinação } \\
(\%)\end{array}$} & 25,1 & 11,0 & 97,50 & 89,55 & 81,40 & 74,44 \\
\hline & 29,4 & 11,0 & 96,50 & 88,09 & 77,91 & 71,89 \\
\hline & 33,4 & 11,0 & 95,50 & 84,60 & 76,20 & 70,65 \\
\hline & 25,1 & 13,0 & 98,00 & 95,60 & 92,39 & 90,35 \\
\hline & 29,4 & 13,0 & 97,83 & 90,73 & 90,18 & 85,96 \\
\hline & 33,4 & 13,0 & 96,16 & 86,31 & 87,31 & 88,12 \\
\hline \multirow{6}{*}{$\begin{array}{c}\text { Danos } \\
(\%)\end{array}$} & 25,1 & 11,0 & 0,00 & 32,30 & 46,05 & 67,10 \\
\hline & 29,4 & 11,0 & 0,00 & 29,60 & 53,45 & 67,70 \\
\hline & 33,4 & 11,0 & 0,00 & 36,25 & 54,20 & 75,65 \\
\hline & 25,1 & 13,0 & 0,00 & 2,50 & 5,40 & 18,25 \\
\hline & 29,4 & 13,0 & 0,00 & 10,95 & 23,45 & 44,85 \\
\hline & 33,4 & 13,0 & 0,00 & 6,70 & 26,75 & 47,20 \\
\hline
\end{tabular}

O teor de umidade inicial também influencia a percentagem final de danos mecânicos causados às sementes. Sementes colhidas com teores de umidade mais elevados são mais susceptíveis a danos mecânicos que aquelas colhidas com menor teor de umidade, mesmo depois de secas, até atingirem um mesmo teor de umidade final.

Pela análise dos resultados apresentados na Tabela 2, concluise que a percentagem de danos mecânicos, a percentagem de germinação e a condutividade elétrica da solução que continha a semente, estão todos correlacionados, e são função da

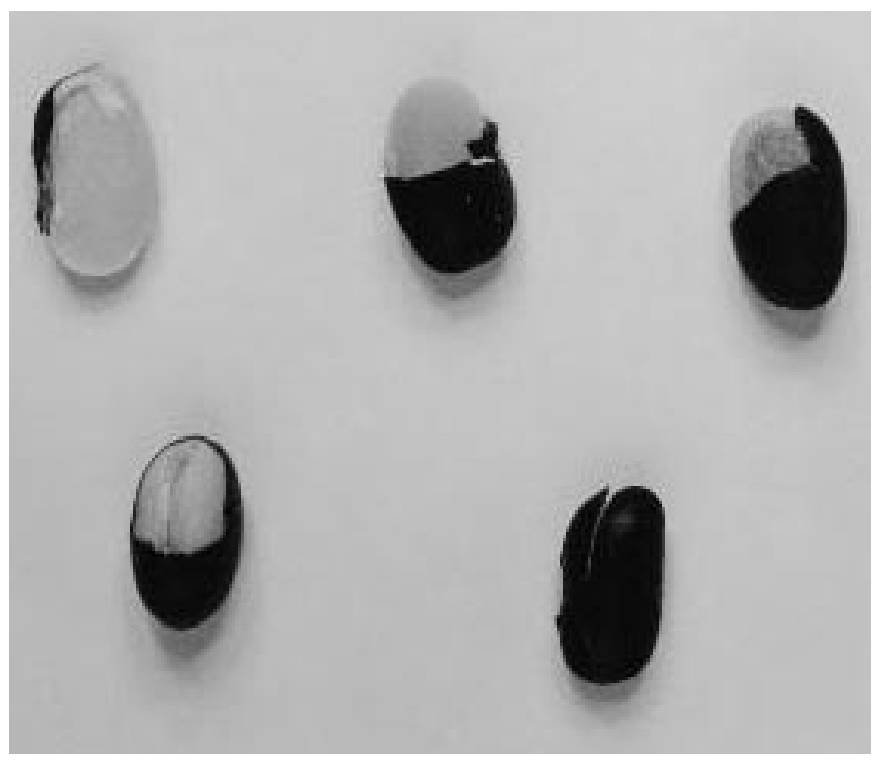

Figura 2. Tipos de danificação causada às sementes de feijão com teores de umidade de 11,0 e $13,0 \%$ b.u., depois de serem impactadas nas velocidades de 10,$0 ; 13,0$ e $16,5 \mathrm{~m} \mathrm{~s}^{-1}$ 
velocidade de impacto mecânico nas sementes. Portanto, esses parâmetros podem ser expressos em função da velocidade de impacto, para constituir uma estimativa da danificação causada à semente por impacto. Então, pode-se estimar a danificação mecânica de três formas diferentes: (1) Variação da percentagem de danos em função da velocidade de impacto; (2) Percentagem de germinação em função da velocidade de impacto; e (3) Variação da condutividade elétrica da solução em função da velocidade de impacto.

Para estimação da danificação mecânica como descrita anteriormente, propôs-se a seguinte equação:

$$
y=a+b \exp (-v)+c \exp (v)
$$

em que:

y - variação do índice de danos (\%), variação da germinação (\%) ou variação da condutividade elétrica da solução $\left(\mu \mathrm{S} \mathrm{cm}^{-1}\right.$ $\left.\mathrm{g}^{-1}\right)$

$\mathrm{v}$ - velocidade de impacto $\left(\mathrm{m} \mathrm{s}^{-1}\right)$

a, b e c - parâmetros da equação

A Tabela 3 apresenta os valores das constantes a, b e c da Equação (1) ajustada aos dados experimentais de condutividade elétrica, percentagem de germinação e percentagem de danos ocorridos nas sementes.

Tabela 3. Valores dos parâmetros da Equação (1) que definem os tratamentos de condutividade elétrica, percentagem de germinação e percentagem de danos ocorridos nas sementes, em função da umidade inicial e umidade final das sementes

\begin{tabular}{|c|c|c|c|c|c|c|}
\hline Caractéristica & Ui (\% b.u.) & Uf (\% b.u.) & a & b & $\mathrm{c}$ & $\mathrm{R}^{2}(\%)$ \\
\hline \multirow{6}{*}{$\begin{array}{l}\text { Condutividade } \\
\text { elétrica } \\
\left(\mu \mathrm{S} \mathrm{cm}^{-1} \mathrm{~g}^{-1}\right)\end{array}$} & 25,1 & 11,0 & 115,0215 & $-34,3717$ & $1,07 \mathrm{E}-08$ & 99,95 \\
\hline & 29,4 & 11,0 & 119,0968 & $-38,4268$ & $2,81 \mathrm{E}-07$ & 99,79 \\
\hline & 33,4 & 11,0 & 135,1092 & $-53,2692$ & $5,20 \mathrm{E}-07$ & 99,99 \\
\hline & 25,1 & 13,0 & 94,4149 & $\begin{array}{l}-17,2649 \\
\end{array}$ & $3,88 \mathrm{E}-07$ & 99,84 \\
\hline & 29,4 & 13,0 & 100,5348 & $-21,0849$ & $2,32 \mathrm{E}-07$ & 99,65 \\
\hline & 33,4 & 13,0 & 107,2073 & $-25,3673$ & $1,56 \mathrm{E}-07$ & 99,77 \\
\hline \multirow{6}{*}{$\begin{array}{c}\text { Germinação } \\
(\%)\end{array}$} & 25,1 & 11,0 & 85,7147 & 11,7855 & $-7,77 \mathrm{E}-07$ & 89,76 \\
\hline & 29,4 & 11,0 & 83,2512 & 13,2490 & $-7,85 \mathrm{E}-07$ & 86,38 \\
\hline & 33,4 & 11,0 & 80,6217 & 14,8785 & $-6,91 \mathrm{E}-07$ & 90,64 \\
\hline & 25,1 & 13,0 & 94,0824 & 3,9177 & $-2,58 \mathrm{E}-07$ & 86,03 \\
\hline & 29,4 & 13,0 & 90,5330 & 7,2971 & $-3,12 \mathrm{E}-07$ & 99,87 \\
\hline & 33,4 & 13,0 & 86,7788 & 9,3812 & $-9,28 \mathrm{E}-08$ & 99,25 \\
\hline \multirow{6}{*}{$\begin{array}{c}\text { Índice de } \\
\text { Danos } \\
(\%)\end{array}$} & 25,1 & 11,0 & 38,6276 & $-38,6280$ & $1,96 \mathrm{E}-06$ & 96,48 \\
\hline & 29,4 & 11,0 & 40,9284 & $-40,9290$ & 1,85E-06 & 89,89 \\
\hline & 33,4 & 11,0 & 44,6060 & $-44,6060$ & 2,14E-06 & 95,27 \\
\hline & 25,1 & 13,0 & 3,7009 & $-3,7010$ & $9,96 \mathrm{E}-07$ & 98,44 \\
\hline & 29,4 & 13,0 & 16,6660 & $-16,6662$ & $1,94 \mathrm{E}-06$ & 93,85 \\
\hline & 33,4 & 13,0 & 16,0885 & $-16,0889$ & 2,14E-06 & 86,53 \\
\hline
\end{tabular}

As Figuras 3, 4 e 5 foram obtidas a partir dos dados estimados usando-se a Equação (1) com os coeficientes apropriados para cada caso (Tabela 3 ).

Observa-se, na Figura 3, que os danos ocorridos às sementes, devido ao choque mecânico em diferentes velocidades, foram explicados adequadamente pela equação proposta, apresentando bom ajuste aos dados experimentais; pode-se observar, também, na mesma figura, os distintos tratamentos de secagem e impacto nas sementes, confirmando que os teores de umidade inicial e final e as velocidades de impacto exercem influência determinante na qualidade final da semente depois de receberem o choque mecânico.

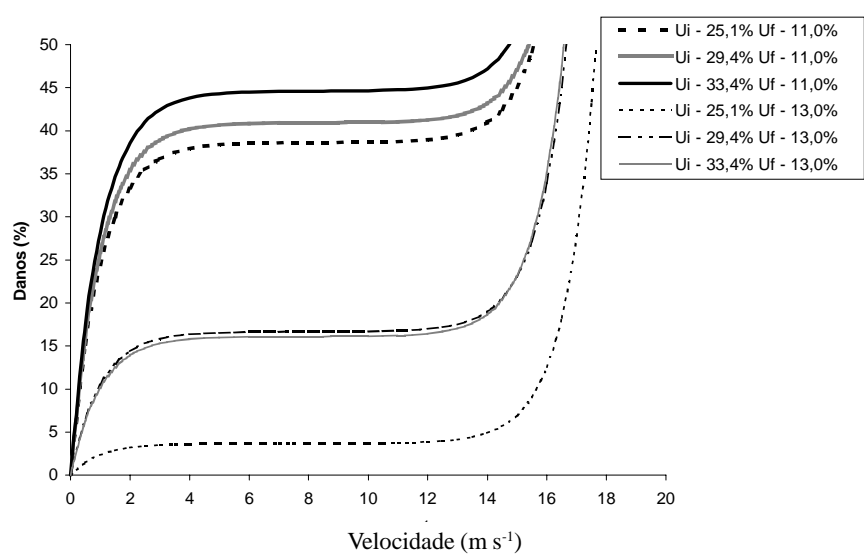

Figura 3. Valores estimados (Eq. 1) para a danificação das sementes de feijão medida pela avaliação visual de danos mecânicos $(\%)$ em função da velocidade de impacto

A Figura 4 apresenta os resultados obtidos pelo ajuste da Equação (1) aos dados de percentagem de germinação das sementes, depois de sofrerem impacto mecânico. Nesta figura observa-se que a velocidade de impacto influenciou significativamente na germinação das sementes e que, quando se elevou a velocidade de impacto, ocorreu redução da germinação, o que é confirmado pelos dados experimentais.

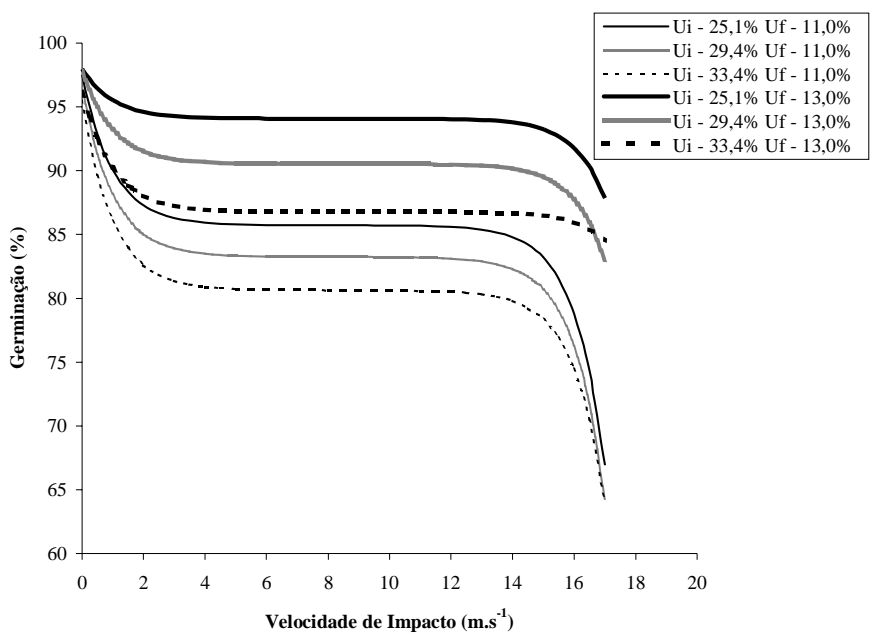

Figura 4. Valores estimados (Eq. 1) da germinação das sementes de feijão depois do impacto nas velocidades de 10,0; 13,0 e $16,5 \mathrm{~m} \mathrm{~s}^{-1}$, avaliado pelo teste-padrão de germinação

Na Figura 5 observa-se que a velocidade do choque mecânico exerce grande influência sobre a condutividade elétrica da solução contendo as sementes. $O$ teste de condutividade elétrica analisa, pela quantidade de lixiviados da solução, o indicativo de vigor da semente, mostrando o grau de degradação das membranas celulares.

Pela Tabela. 2 e Figuras 3, 4 e 5, a velocidade de impacto de $16,5 \mathrm{~m} \mathrm{~s}^{-1}$ foi a que causou maiores danos às sementes, sendo responsável pela menor percentagem de germinação, enquanto a velocidade de impacto de $10,0 \mathrm{~m} \mathrm{~s}^{-1}$ foi a que menos danos causou, com os melhores resultados de germinação, cujo resultado é similar ao encontrado por Moraes (1980) e Bartsch et al. (1984). Para todos os tratamentos, as sementes com $11,0 \%$ de umidade apresentaram maior susceptibilidade à queda de qualidade, devido ao choque mecânico. Verifica-se, também, 
na Tabela 2, que para as velocidades de 13,0 e $16,5 \mathrm{~m} \mathrm{~s}^{-1}$, com teor de umidade de $11,0 \%$ b.u., a percentagem de germinação atingiu valores inferiores aos estabelecidos para comercialização de sementes de feijão no Estado de Minas Gerais para o ano agrícola 1996/1997 (mínimo de 80\% de germinação).

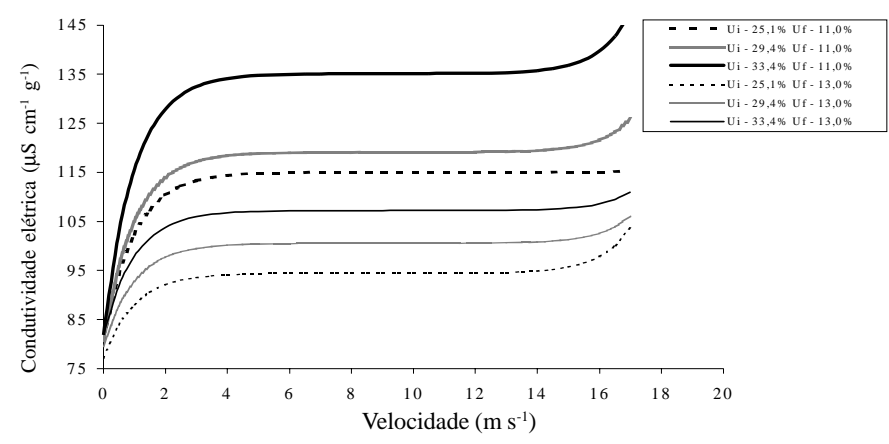

Figura 5. Valores estimados (Eq. 1), para a danificação das sementes de feijão medida pela condutividade elétrica da solução contendo as sementes em função da velocidade de impacto

Verifica-se, nas curvas estimadas pela Equação (1), na Figura 5 e na Tabela 2, que as sementes que receberam impacto com a maior velocidade $\left(16,5 \mathrm{~m} \mathrm{~s}^{-1}\right)$ foram, também, as que apresentaram maior valor de condutividade elétrica, evidenciando o efeito do choque mecânico no comprometimento da integridade dos tecidos das sementes impactadas; conclusão semelhante foi encontrada por Couto et al. (1998) trabalhando na elaboração de um método quantitativo de avaliação de danos mecânicos em sementes de soja, por meio da condutividade elétrica, variando a intensidade do dano e o tempo de embebimento com e sem agitação mecânica da solução com as sementes; já as sementes com teor de umidade final de 11,0\% b.u. apresentaram-se mais danificadas e, conseqüentemente, com menor vigor que aquelas com $13,0 \%$ b.u., indicando que o teor de umidade final da semente é fator determinante na susceptibilidade das sementes a danos provocados por impactos ou choques mecânicos, o que é observado claramente na Figura 5.

Observa-se, nesta figura que, quanto maior o teor de umidade das sementes, maior é a sua capacidade de absorver os impactos, ocasionando menor comprometimento de suas membranas celulares, para uma análise de qualidade. Esses resultados apresentam a mesma tendência dos resultados encontrados por Pickett (1973) que, trabalhando com feijão, concluiu que a velocidade e o teor de umidade final são fatores que determinam a intensidade do dano.

O teor de umidade inicial teve influência significativa sobre a qualidade fisiológica das sementes depois de secas e impactadas. Para um mesmo valor de umidade final, a condutividade elétrica tende a diminuir quando a umidade inicial das sementes é menor. Para a umidade inicial mais elevada $(33,4 \%$ b.u. ) combinada com a umidade final mais baixa $(11,0 \%$ b.u.) e a velocidade de impacto mais elevada $\left(16,5 \mathrm{~m} \mathrm{~s}^{-1}\right)$ observase elevação significativa da condutividade elétrica da solução; sendo assim, sementes de feijão colhidas com teor de umidade mais elevado, para posterior secagem, conforme observado no experimento, provavelmente apresentarão maior susceptibilidade a danos mecânicos.
Quando uma semente seca é colocada para embeber em água, verifica-se uma rápida embebição no início, associada à lixiviação de eletrólitos do interior das células para o meio externo, devido a uma provável desestruturação das membranas celulares no processo de secagem (Vieira \& Carvalho, 1994); por isto, podem ocorrer pequenas variações nos resultados de condutividade elétrica para sementes de uma mesma amostra, mas com teor de umidade diferente. Para as sementes impactadas com teor de umidade de $11,0 \%$ b.u., os resultados de condutividade elétrica foram superiores àqueles para sementes com $13,0 \%$ b.u.; isto se deve, provavelmente, ao fato de as sementes com teor de umidade de $11,0 \%$ b.u. terem sofrido maior efeito do impacto mecânico e também ao maior tempo de secagem a que elas foram submetidas.

Pelas Figuras 3, 4 e 5 pode-se observar que as curvas das equações ajustadas para percentagem de danos mecânicos, percentagem de germinação e condutividade elétrica da solução contendo as sementes, depois de aproximadamente $6 \mathrm{~m} \mathrm{~s}^{-1} \mathrm{e}$ até aproximadamente $11 \mathrm{~m} \mathrm{~s}^{-1}$, apresentam-se praticamente constantes quanto a variação da qualidade; isto se deve, sem dúvida, ao fato dos dois valores experimentais próximos a esses pontos também não apresentarem tendência à substancial variação e também pelo fato do ajuste ter sido feito com a utilização de apenas quatro pontos experimentais, ou seja, quatro velocidades de impacto.

A análise dos resultados obtidos indica que a equação ajustada para medir o nível de danificação às sementes pelo impacto mecânico, utilizando-se o teste de condutividade elétrica, foi satisfatória, apresentando coeficientes de determinação $\left(\mathrm{r}^{2}\right)$ superiores a 0,99 , e a velocidade de $16,5 \mathrm{~m} \mathrm{~s}^{-1}$ foi a que causou maior quebra de membranas celulares e queda de qualidade nas sementes de feijão.

\section{CONCLUSÕES}

A análise dos resultados obtidos levou às seguintes conclusões:

1. A equação ajustada para medir o nível de danificação às sementes pelo impacto mecânico, utilizando-se o teste de condutividade elétrica, foi satisfatória, apresentando coeficiente de determinação superior a 99\%, podendo ser utilizada na avaliação de danos mecânicos em sementes.

2. O aumento da velocidade de impacto causou maior queda de qualidade nas sementes de feijão.

3. Sementes colhidas com teor de umidade mais elevado são mais susceptíveis à danificação mecânica, depois de secas.

\section{REFERÊNCIAS BIBLIOGRÁFICAS}

ARAÚJO, E.F.; SILVA, R.F.; SILVA, J. S.; SEDIYAMA, C.S. Influência da secagem e debulha das vagens na germinação e no vigor de sementes de feijão. Revista Brasileira de Sementes, Brasília, v.6, n.2, p. 97-110, 1984.

BARTSCH, J.A.; HAUGH, C.G.; ATHOW, K.L.; PEART, R.M. Impact damage to soybean seed. Transactions of the ASAE, St. Joseph, v.27, n.2, p.582-586, 1984. 
BRASIL. Ministério da Agricultura e Reforma Agrária. Regras para análise de sementes, Brasília, DF, 1992. 365p.

CARVALHO, N.M.; NAKAGAWA, J. Sementes: ciência, tecnologia e produção. 3. ed. Campinas, SP: Fundação Cargil, 1988. 424p.

CHAVES, M.A.; MOREIRA, S.M.C.; ALVARENGA, L.C.; OLIVEIRA, L.M. Efeito de múltiplos impactos na germinação de três cultivares de sementes de soja. Revista Brasileira de Armazenamento, Viçosa, v.17, n. 1/2, p. 2-9, 1992.

COSTA, N.P.; MESQUITA, C.M.; HENNING, A.A. Avaliação de perdas e dos efeitos da colheita mecânica sobre a qualidade fisiológica e a incidência de patógenos em sementes de soja. Revista Brasileira de Sementes, Brasília, v.1, n.3, p. 59$70,1979$.

COUTO, S.M.; SILVA, M.A.; REGAZZI, A.J. An electrical conductivity method suitable for quantitative mechanical damage evaluation. Transactions of the ASAE, St. Joseph, v.41, n.2, p.421-426, 1998.

EVANS, M.D.; HOLMES, R.G.; McDONALD, M.B. Impact damage to soybean seed as affected by surface hardness and seed orientation. Transactions of the ASAE, St. Joseph, v.33, n.1, p.234 - 240, 1990.

GUNASEKARAN, S.; MUTHUKUMARAPPAN, K. Breakage susceptibility of corn of different stress-crack categories. Transactions of the ASAE, St. Joseph, v. 36, n.5, p. 1445 1446, 1993.

HESLEHURST, M.R. Quantifying initial quality and vigour of wheat seeds using regression analysis of conductivity and germination data from aged seeds Seed Science \& Technology, Zurich, v. 16, p. 75-85, 1988.
KRZYZANOWSKI, F.C.; FRANÇA NETO, J.B.; HENNING, A.A. Relato dos testes de vigor disponíveis para grandes culturas. Informativo ABRATES Brasília, v.1, n.2, p.15 - 50, 1991.

MATTHEWS, S.; ROGERSON, N.E. The influence of embryo condition on the leaching of solutes from pea seeds. Journal of Experimental Botany, Oxford, v. 27, n. 100, p. 961968, 1976.

MORAES, M.L.B. Efeitos da velocidade e da posição do impacto na germinação e vigor de sementes de soja (cultivar UFV - 2) com diferentes teores de umidade. Viçosa, MG: UFV, 1980. 38p. Dissertação Mestrado

NEWBERY, R.S.; PAULSEN, M.R.; NAVE, W.R. Soybean quality with rotary and conventional threshing. Transactions of the ASAE, St. Joseph, v. 23, n.2, p. 303 - 308, 1980.

PAULSEN, M.R.; NAVE, W.R.; GRAY, L.E. Soybean seed quality as affected by impact damage. Transactions of the ASAE, St. Joseph, v. 24, n.6, p. 1577 - 1582, 1981.

PICKETT, L.K. Mechanical damage and processing loss during navy bean harvesting. Transactions of the ASAE, St. Joseph, v.16, n.6, p. 1047 - 1050, 1973.

RADAJEWSKI, W.; JENSEN, T.; ABAWI, G.Y.; McGAHAN, E.J. Drying rate and damage to navy beans. Transactions of the ASAE, St. Joseph, v.35, n.2, p. 583 - 590, 1992.

SANTOS, J.R. Caracterização física e danos causados por impactos em castanha-do-Brasil. Viçosa, MG: UFV, 1976. 48p. Dissertação Mestrado

VIEIRA, R.D.; CARVALHO, N.M. Testes de vigor em sementes. Jaboticabal: FUNEP/UNESP, 1994. p.103-132.

VIEIRA, R.F.; VIEIRA, C.; RAMOS, J.A.O. Produção de sementes de feijão. Viçosa, MG: EPAMIG, 1993. 131p. 